\title{
LXXVII. Gradual modification of the first linear spectra of emission of mercury
}

\section{Prof. Enrico Castelli}

To cite this article: Prof. Enrico Castelli (1907) LXXVII. Gradual modification of the first linear spectra of emission of mercury, Philosophical Magazine Series 6, 14:84, 784-785, DOI: $10.1080 / 14786440709463740$

To link to this article: http://dx.doi.org/10.1080/14786440709463740

册 Published online: 16 Apr 2009.

Submit your article to this journal $[\pi$

Џlll Article views: 3

Q View related articles $\square$

4 Citing articles: 2 View citing articles ๘ 


\section{First Linear Spectra of Emission of Mercury.}

It is improbable that the sodium plays more than an indirect part in the generation of the gas. The following suggestion seems at least probable. The presence of a trace of sodium in aluminium renders it, as is well known, capable of decomposing water, so that an electrode of such metal becomes charged with hydrogen, probably chemically combined as hydride, by mere exposure to air. The unknown gas may be a modification of hydrogen like ozone is of oxygen, capable of withstanding the discharge of an influence machine, but decomposed by the discharge of a coil. This theory is being investigated.

The question of the quality of aluminium used for the purposes of electrodes is of great practical importance. Of old, aluminium was manufactured by a process which rendered the presence of sodium unavoidable. A trace of sodium is, however, a very undesirable impurity technically on account of the metal being attacked by moisture, and the most strenuous efforts of recent years have been directed to increasing the purity of the metal for technical purposes, with the result that the aluminium to-day differs entirely from that first made. It is a very unsuitable material for the construction of electrodes, the discbarge passing with difficulty and irregularity. Too great purity of the British aluminium may serve to explain some of the difficulties besetting the X-ray bulb manufacturers in this country.

We are indebted to the Carnegie Trust for the provision of the instruments used in this investigation.

Physical Chemistry Laboratory, The University, Glasgow.

LXXVII. Gradual Modification of the First Linear Spectra of Emission of Mercury. Preliminary Note by Prof. EnRioo Castelli *.

[Plate XVII.]

Y WHE recent discoveries made by Sir W. Ramsay on the transformation of several elementary substances, which were lately mentioned at the Congress at Parma of the Italian Association for the Progress of Science, have recalled in my mind a fact I observed about a year ago, in studying the luminous spectra of mercury.

I had found that in taking (with a Steinheil spectrograph, fitted with three quartz prisms) some spectrophotographs of the electric are in the vapour of mercury, contained in a Uviol lamp, the spectrum lines (amounting only to 16 , on account of the limited dispersion of the apparatus), while remaining constant in position, showed in time a gradual variation of their photochemical action: the lines corre-

* Communicated by Sir Wm. Ramsar, F.R.S. 
sponding to less refrangible monochromatic rays gradually became more intense, and produced on the orthochromatic plates a greater and greater effect ; while the contrary occurred with the more refrangible lines.

Having lately made a new spectrograph of the light emitted by the above-mentioned lamp, I found that the group of three lines, of the wave-lengths $3663 \cdot 3,3654 \cdot 9$, and $3650 \cdot 3$ Angström units, had nearly completely vanished; while the three lines $5790 \cdot 49,5769 \cdot 45$, and $5460^{\circ} \cdot 97$, which in the first experiments had given a scarcely visible photographic impression, now produced a much clearer and a more intense impression than any other line!

The figure accompanying this note shows the comparison of two spectrographs of the light emitted by the electric arc in mercury vapour, the former of which was made when the Uviol lamp was almost new ; the latter after the same lamp (always fed by a continuous current of 60 volts and 2 to 3 amperes) had been working diuring short periods separated by long intervals, for about one hundred hours.

As it is now generally believed that the vibration corresponding to each line of the spectrum of an element must be considered as due to its positive ions, I think the modification I have noticed in what Prof. Stark calls the first linear spectrum of mercury, must be considered as depending on an alteration in the character of the positive monovalent ions. probably consisting in such a variation of the vibrating mass, that it renders oscillations of a higher frequency impossible, while the vibrations of less wave-length, due to a state of a smaller capacity for motion, are made easier and therefore intensified.

We have still to find out whether this observation as to probable material modification of mercury can be further corroborated, and also whether it can even become permanent, corresponding to a change in the internal constants of mercury; and this I intend to be the subject for further experimental researches.

Padua, R. Istituto Technico, October 5th, 1907.

\section{Proceeaings of Learned Societies. GEOLOGICAL SOCIETT. [Continued from p. 6.76.]}

June 19th, 1907.-Aubrey Strahan, M.A., F.R.S., Vice-President, in the Chair.

' ${ }^{H E}$ following communications were read:-

1. 'The Inferior Oolite and Contiguous Deposits of the BathDoulting District.' By Linsdall Richardson, F.G.S.S.

2. "The Inferior Oolite and Contiguous Deposits of the District 


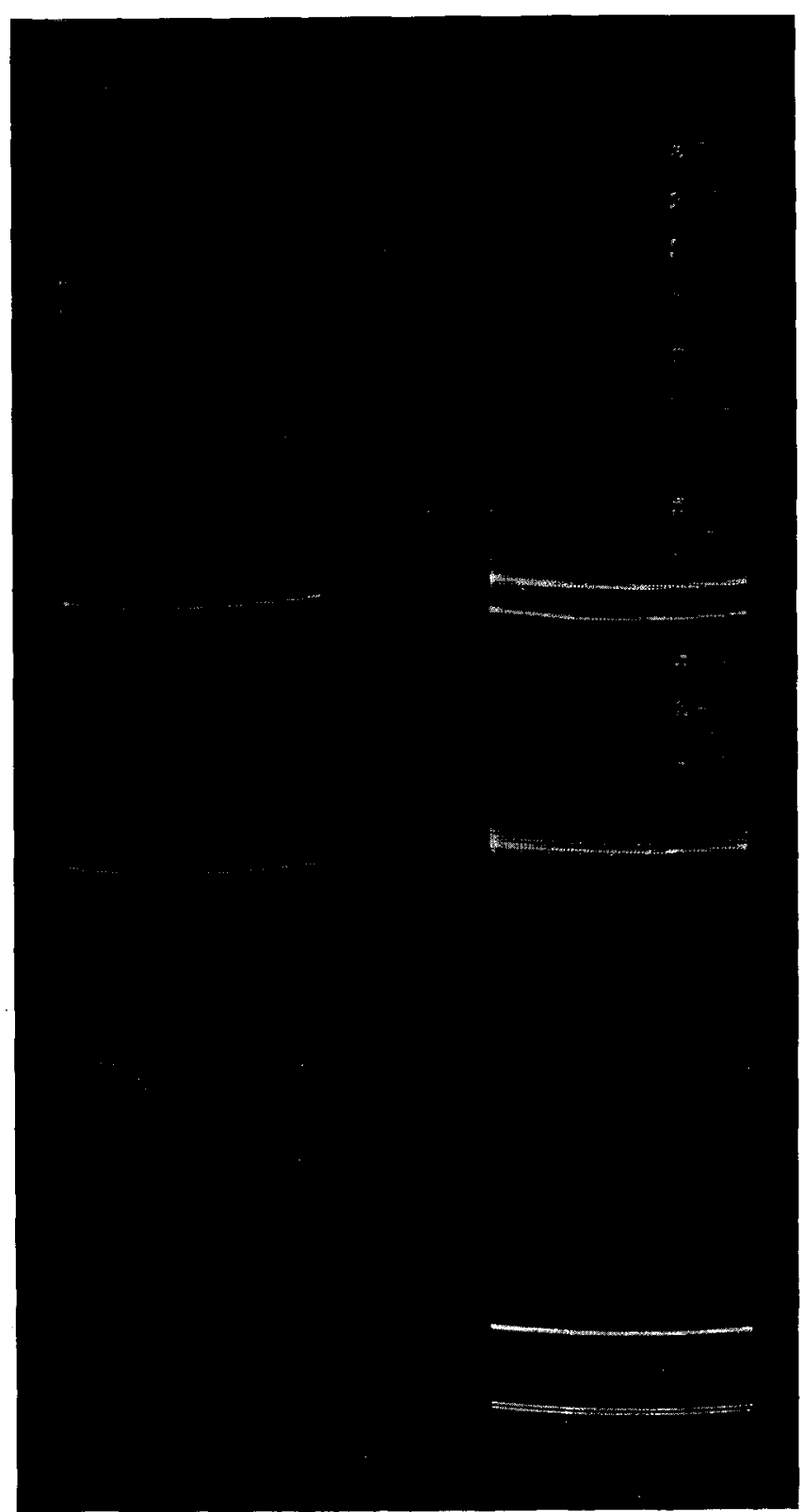

